\title{
Peran Mediasi Job Satisfaction terhadap Public Service Motivation (PSM) dan Organizational Citizenship Behaviour (OCB)
}

\author{
Anna Zahroh Uswatun Chasanah \\ Magister Manajemen, Universitas Indonesia \\ ni.anna.22@gmail.com \\ Putri Mega Desiana \\ Manajemen, Fakultas Ekonomi dan Bisnis, Universitas Indonesia \\ putri.mega71@ui.ac.id
}

Diterima 22 Februari 2018, Disetujui 02 Mei 2018

\begin{abstract}
Abstrak
Penelitian ini membahas mengenai pengaruh public service motivation (PSM) dan job satisfaction terhadap organizational citizenship behaviour (OCB) di Kantor Pertanahan Kota Administrasi Jakarta Selatan. Peningkatan pelayanan publik menjadi prioritas pemerintah sebagai upaya memenuhi keinginan masyarakat. Pemerintah mencanangkan reformasi birokrasi untuk meningkatkan kinerja aparatur sipil negara. Kinerja pegawai berkaitan dengan adanya motivasi, kepuasan kerja agar dapat memberikan pelayanan lebih kepada masyarakat. Penelitian ini dilakukan pada 108 responden dari total populasi 131 pegawai, dengan tujuan untuk mengetahui pengaruh public service motivation (PSM) dan job satisfaction terhadap organizational citizenship behaviour (OCB). Data yang terkumpul kemudian diolah menggunakan aplikasi SPSS versi 22.0. Hasil penelitian menunjukkan public service motivation berpengaruh secara langsung terhadap kepuasan kerja, serta berpengaruh terhadap organizational citizenship behaviour. Semakin meningkatnya public service motivation (PSM) ternyata meningkatkan job satisfaction pegawai, dan dengan meningkatnya public service motivation (PSM) juga job satisfaction ternyata berpengaruh dalam meningkatkan organizational citizenship behaviour (OCB), selain itu penelitian ini juga menemukan bahwa public service motivation dapat berpengaruh secara langsung ke organizational citizenship behaviour (OCB) meskipun tanpa dimediasi oleh job satisfaction. Hasil ini dapat membantu organisasi lain yang memiliki karakteristik sama dengan Kantor Pertanahan Jakarta Selatan dalam mengidentifikasi strategi yang bisa dilakukan untuk meningkatkan organizational citizenship behaviour (OCB).
\end{abstract}

Kata Kunci : Perilaku Kewarganegaraan Organisasional, Kepuasan Kerja, Motivasi Pelayanan Publik

Abstract

This research discusses the influence of public service motivation (PSM) and job satisfaction towards organizational citizenship behavior (OCB) in South Jakarta Municipal Administration Office. Improving public services is a priority of the government as an effort to fulfill people's wishes. The Government proclaimed bureaucratic reforms to improve the performance of the state civil apparatus. Performance of employees associated with the motivation, job satisfaction in order to provide more services to the community. This study was conducted on 108 respondents from the total population of 131 employees, with the aim to know the influence of public service motivation (PSM) and job satisfaction towards organizational citizenship behavior (OCB). The collected data is then processed using SPSS application version 22.0. The results showed that public service motivation has a direct effect on job satisfaction, as well as an effect on organizational citizenship behavior. The increasing of public service motivation (PSM) is increasing the employee's job satisfaction, and with the increase of public service motivation (PSM) also job satisfaction has an effect on improving organizational citizenship behavior (OCB), besides this research also found that public service motivation can influence directly to organizational citizenship behavior (OCB) even without mediation by job satisfaction. These results can help other organizations with similar characteristics to the South Jakarta Land Office in identifying strategies that can be done to improve organizational citizenship behavior (OCB).

Keywords : Organizational Citizenship Behavior, Job Satisfaction, Public Service Motivation 


\section{PENDAHULUAN}

Presiden Republik Indonesia, Joko Widodo dalam pemerintahannya melalui Kabinet Kerja berupaya menjalankan reformasi birokrasi dengan cara peningkatan partisipasi publik serta transparansi tata kelola pemerintahan (Webstite Presiden RI, 2015). Dalam praktek penyelenggaraan pelayanan publik, masih terjadi adanya penyimpangan, diskresi, keberanian melakukan spekulasi, sehingga inovasi dan pelanggaran memiliki jarak yang sangat tipis (Puslitbang BPN RI, 2015). Masyarakat menuntut pemerintah memberikan pelayanan publik yang lebih baik, karena kinerja pelayanan publik yang dilaksanakan oleh pemerintah dinilai masih kurang memuaskan (Mukarom \& Laksana, 2015).

Jumlah laporan terhadap layanan publik terus meningkat. Pada tahun 2015 terdapat 5.600 laporan, tahun 2016 meningkat sekitar 7.000 lebih laporan, tahun 2017 hampir 9.000 laporan, dan baru awal tahun 2018 saja, telah masuk hampir 300 laporan ke Ombudsman RI (Ombudsman RI, 2018). Pengaduan paling banyak terkait dengan penegakan hukum yaitu kepolisian, kejaksaan dan pengadilan, diikuti kemudian dengan pengaduan di bidang pertanahan, terkait perizinan di daerah, dan terakhir masalah kesehatan dan pendidikan. Terkait pengaduan di bidang pertanahan, Kementerian Agraria dan Tata Ruang/BPN (Kemen ATR/BPN) merupakan instansi yang bertanggungjawab untuk melaksanakan tugas pemerintah di bidang pertanahan.

Pelayanan publik yang baik tercermin dari kinerja pegawainya. Kinerja yang baik tentu saja merupakan harapan bagi semua perusahaan dan institusi, sebab kinerja pegawai ini pada akhirnya diharapkan dapat meningkatkan kinerja perusahaan secara keseluruhan. Robbins \& Judge (2013) mengemukakan bahwa kesuksesan organisasi membutuhkan pegawai yang mau melakukan tugasnya lebih dari yang diharapkan. Perilaku atau tindakan ekstra yang melebihi dari peran yang ditentukan oleh organisasi ini disebut sebagai Organizational Citizenship Behaviour (OCB). Hal ini sejalan dengan penelitian yang dilakukan oleh Smith et. al. (1983) yang menyatakan bahwa OCB merupakan kategori dari kinerja. MacKenzie, et. al dalam Podsakoff (2000) menyarankan beberapa alasan mengapa manajerial perlu menilai OCB dan memasukkannya dalam daftar ketika melakukan penilaian kinerja pegawai. Memiliki pegawai yang dapat mengerti tanggung jawab serta mau berbuat lebih untuk organisasinya merupakan hal yang sangat diinginkan setiap pemimpin organisasi, namun bagaimana memunculkan OCB tersebut tentunya memerlukan pendorong agar setiap pegawai mau melakukan tanpa paksaan. Motivasi dalam diri pegawai merupakan faktor internal yang turut mempengaruhi bagaimana seseorang akan melaksanakan tugas dan kewajibannya. Perry \& Wise (1996) berpendapat bahwa bagaimana motivasi pelayanan publik (Public Service Motivation) berkontribusi terhadap komitmen organisasi dan kinerjanya merupakan hal yang sangat penting untuk dipahami. Konsep Public Service Motivation (PSM) merupakan pengembangan dari penjelasan perilaku manusia dari perspektif norma dan afektif, setelah "The Motivational Bases of Public Service” mereka publikasikan pada tahun 1990.

Hasil studi Cun (2012) menunjukkan semakin lama seseorang memiliki masa kerja maka PSM mulai menurun. Penyebab hal tersebut masih perlu dipelajari lebih lanjut apakah dikarenakan oleh kebosanan psikologis yang disertai dengan adanya pengulangan karakteristik prosedural pekerjaan di sektor publik, ataukah frustasi karena adanya persepsi mengenai birokrasi di sektor publik. Studi tersebut senada dengan penelitian OCB oleh Robbins \& Judge (2013) yang menyatakan bahwa OCB bukan sebagai bagian dari tugas resmi pekerjaan, namun merupakan kontribusi dari psikologis dan lingkungan sosial dari tempat bekerja. Lebih lanjut, hubungan antara PSM dengan OCB ini didukung oleh hasil studi Kim (2006) yang menyatakan adanya pengaruh signifikan antara PSM dengan OCB.

Tidak hanya PSM yang dapat mempengaruhi OCB. Beberapa penelitian sebelumnya membuktikan adanya pengaruh dari job satisfaction terhadap OCB (Cun, 2012; Liu, Tang \& Zhu, 2008; Rast \& Taurani, 2012). Cun melakukan studinya terhadap pegawai pemerintah China, dalam studinya Cun juga meneliti pengaruh PSM terhadap OCB. Cun membagi responden berdasarkan tingkatan level karier dan tingkat kematangan responden dalam pekerjaan, dilihat dari lamanya bekerja. Hasil yang diperoleh menunjukkan bahwa PSM secara signifikan mempengaruhi kepuasan kerja dan OCB. Hasil yang sama juga ditunjukkan oleh studi Sunaryo (2013) yang melakukan penelitian pada Pemda Sragen.

Kepuasan kerja yang dapat mempengaruhi OCB terbukti dapat menjadi mediator antara PSM dan OCB. Hal ini berarti pengaruh PSM ke OCB tidak hanya pengaruh langsung, namun juga pengaruh tidak langsung dengan melalui kepuasan kerja terlebih dahulu. Hal ini sejalan dengan penelitian yang dilakukan oleh Sunaryo (2013) yang menyatakan bahwa PSM mempengaruhi kepuasan kerja dan 
kepuasan kerja mempengaruhi OCB dalam bentuk altruism dan compliance. Namun hasil yang berbeda diperoleh Kim (2006) ketika melakukan penelitian antara PSM, kepuasan kerja dengan OCB, hasil yang diperoleh walaupun PSM secara signifikan mempengaruhi OCB tetapi tidak ada bukti yang menunjukkan kepuasan kerja mempengaruhi OCB.

Melihat hasil berbagai penelitian di atas, Kantor Pertanahan Kota Administratif Jakarta Selatan tentunya membutuhkan kontribusi dari setiap pegawai untuk pelayanan optimal kepada masyarakat. Pemilihan Kantor Pertanahan Kota Administrasi Jakarta Selatan sebagai obyek penelitian adalah karena Kantor Pertanahan Jakarta Selatan masuk dalam sampel penelitian Indeks Kepuasan Masyarakat pada tahun 2015 dengan kategori berkas pelayanan tinggi. (Indeks Kepuasan Masyarakat, 2015). Hal ini membuat peneliti ingin mengetahui faktor-faktor yang terkait dengan pelayanan tersebut, terutama apakah Public Service Motivation mempengaruhi Organizational Citizenship Behaviour baik secara langsung ataupun tidak langsung, dengan kepuasan kerja sebagai mediasinya di Kantor Pertanahan Kota Jakarta Selatan. Kontribusi adalah penelitian ini adalah hasil temuan diharapkan dapat mempertajam teori-teori yang telah diteliti sebelumnya mengenai pengaruh mediasi kepuasan kerja terhadap Public Service Motivation dan Organizational Citizenship Behavior.

\section{KAJIAN TEORI}

\section{Organizational Citizenship Behaviour}

Organ (1988) mendefinisikan OCB sebagai perilaku individu yang bebas, yang tidak secara langsung atau eksplisit diakui oleh sistem pemberian penghargaan resmi, namun secara agregat mempromosikan fungsi organisasi secara efektif. Joireman, Falvy \& Kamdar, (2006) dalam penelitiannya menyimpulkan bahwa OCB adalah ketika karyawan perusahaan melakukan pekerjaan sesuai dengan fungsi dan tanggung jawabnya dengan baik, namun ada perilaku karyawan yang bekerja dengan melebihi fungsi dan tanggung jawab yang diharapkan. OCB ditampilkan dalam perilaku di pekerjaan misalnya dengan membantu rekan kerja secara sukarela yang dilakukan karyawan karena ia menginginkannya namun hal tersebut bukan kewajibannya (LePine et al., 2002)

Secara sedehana OCB merupakan perilaku di atas dan melebihi kewajiban pekerjaan yang tidak selalu diberi imbalan dengan sistem imbalan organisasi tradisional.
Dimensi Organizational Citizenship Behaviour Smith, Organ \& Near (1983) membagi OCB kedalam 2 (dua) dimensi, yaitu altruism dan generalized compliance.

a. Altruism; yaitu perilaku yang secara langsung dan sengaja bermaksud untuk membantu orang lain dalam situasi tatap muka, misalnya mengajari teman baru, membantu teman yang memiliki pekerjaan berlebih (Smith, Organ \& Near, 1983).

b. Generalized compliance; yaitu berkaitan dengan bentuk yang lebih impersonal, yaitu bantuan yang diberikan tidak langsung pada satu orang tertentu, namun secara tidak langsung dapat membantu orang lain yang terlibat dalam sistem.

\section{Public Service Motivation}

Public Service Motivation (PSM) menurut Perry \& Wise (1990) sebagai kecenderungan seseorang untuk merespon motif berdasarkan sesuatu yang unik atau utama baginya pada lembaga publik atau organisasi, yang dimaksud motif adalah adanya kekurangan atau kebutuhan secara psikologis yang dirasa perlu dipaksa untuk dihilangkan. Brewer \& Selden (1998) menggambarkan PSM sebagai kekuatan motivasi yang membuat atau mendorong seseorang untuk memberikan pelayanan publik yang berarti. Dimensi Public Service Motivation.

Perry (1996) membagi PSM menjadi 4 (empat) dimensi, yaitu : attraction to public policy making, commitment to public interest/civic duty, compassion dan self sacrifice. Attraction to public policy making; menurut Kelman dalam Perry (1996). yaitu adanya kesempatan untuk berpartisipasi dalam perumusan kebijakan publik, Commitment to public interest/civic duty; yaitu keinginan untuk melayani kepentingan publik, menurut Downs dalam Perry (1996), Compassion; yaitu menurut Frederickson dan Hart dalam Perry (1996) sikap yang berkaitan dengan moral, Self sacrifice; yaitu sikap kesediaan berkorban atau melayani orang lain sebagai bentuk subtitusi pencapaian diri (Perry, 1996).

\section{Job Satisfaction}

Kepuasan kerja adalah kumpulan perasaan atau respon afektif yang berhubungan dengan situasi kerja, atau perasaan seseorang atas aspek yang berbedabeda dari pekerjaannya (Spector, 1997). Kreitner \& Kinicki (2014) juga mengaitkan hal tersebut dengan motivasi kerja individual, karena kepuasan kerja adalah respons yang bersifat mempengaruhi terhadap berbagai segi pekerjaan seseorang.

Beberapa penelitian menyarankan bahwa 
kepuasan kerja berkaitan dengan perilaku kerja yang lebih bersifat sukarela dan tidak secara khusus diharuskan bagi pekerja (George \& Jones, 2004). Hal ini berarti merujuk pada Organizational Citizenship Behaviour yaitu perilaku yang melampaui dari panggilan tugas. Perilaku tersebut tidak secara resmi diminta oleh organisasi namun juga diperlukan untuk keberlanjutan dan kefektifan organisasi dan dapat berdampak pada kinerja organisasi. Penelitian yang dilakukan oleh Shokrkon \& Naami (2008) menemukan hubungan antara kepuasan kerja dengan OCB dan kinerja organisasi.

\section{METODE}

Populasi penelitian ini adalah para pegawai tetap di Kantor Pertanahan Jakarta Selatan pada bulan Januari 2017 sampai dengan bulan Maret 2017, sedangkan metode yang digunakan dalam pengambilan sampel pada penelitian ini adalah dengan teknik non probability sampling, dengan metode purposive sampling. Kuesioner dibagikan merata ke semua pegawai di Kantor Pertanahan Kota Administratif Jakarta Selatan, sejumlah 131 orang, namun hanya kembali sebanyak 108 eksemplar.

Model penelitian ini mengadaptasi dari penelitian Cun (2012) yang meneliti pengaruh Public Service Motivation dan kepuasan kerja terhadap Organizational Citizenship Behaviour pada pegawai pemerintah di Ghuangzou, China, namun penelitian tersebut telah dimodifikasi dikarenakan terdapat faset-faset lain dari tiap variabel yang ingin diketahui peneliti, sesuai dengan subjek yang dipilih oleh peneliti. Model dalam penelitian ini seperti terlihat dalam Gambar 1 berikut:

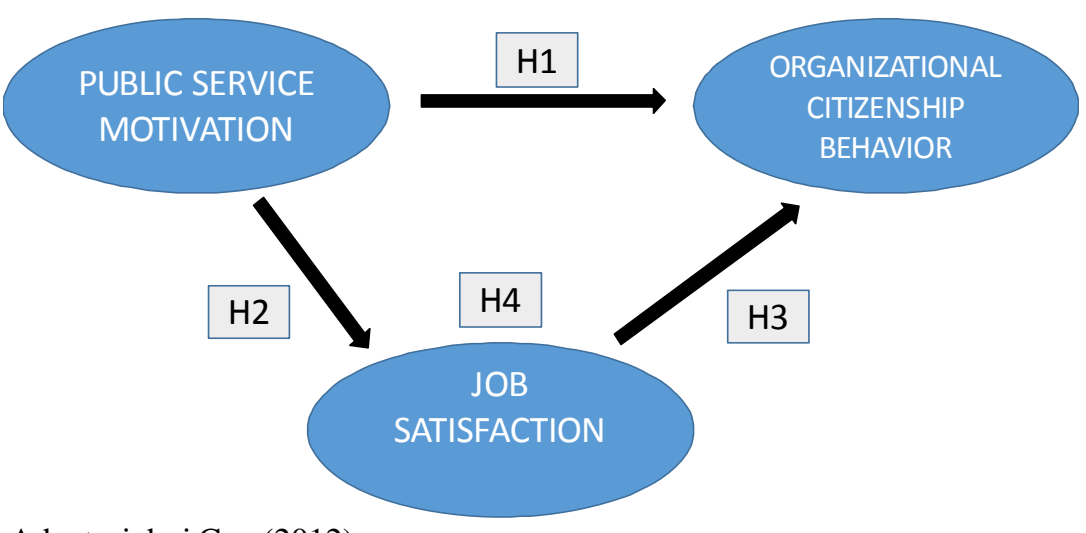

Sumber : Adaptasi dari Cun (2012)

Gambar 1. Model Penelitian

Pada penelitian ini variabel bebas yaitu public service motivation. Konsep public service motivation yang digunakan pada penelitian ini mengadopsi dari hasil penelitian Perry dan Wise (1996) yang memiliki 4 (empat) dimensi, yaitu: attraction to policy making, commitment to public interest/ civic duty, compassion, dan self sacrifice. Variabel terikat dalam penelitian ini adalah organizational citizenship behaviour. Konsep organizational citizenship behaviour pada penelitian ini menggunakan teori dari Smith, Organdan Near (1983) yang memiliki 2 dimensi yaitu: altruism dan general compliance. Variabel mediasi dalam penelitian ini adalah kepuasan kerja. Konsep dari kepuasan kerja pada penelitian ini menggunakan Minnesota Satisfaction Questionnaire dari penelitian Weiss et al (1967), yang memiliki 20 (dua puluh) indikator pertanyaan.

Seperti yang telah dijelaskan sebelumnya, dari penelitian-penelitian terdahulu terdapat pengaruh antara ketiga variabel yang diteliti, yang dapat dijadikan hipotesis dalam penelitian ini, seperti yang dapat dilihat pada Tabel 1 berikut:

Tabel 1. Hipotesis Penelitian

\begin{tabular}{|c|c|}
\hline K od e & $\begin{array}{r}\text { H ip o tes is } \\
\end{array}$ \\
\hline H 1 & $\begin{array}{l}\text { Public Service Motivation m e m iliki } \\
\text { Organgational Citizenship Behaviour }\end{array}$ \\
\hline H 2 & $\begin{array}{llllll}\text { Public Service } & \text { Motivation m e m iliki } & \text { pengaruh } & \text { langsung terhadap } \\
\text { Kepuasan Kerja } & & & & \\
\end{array}$ \\
\hline H 3 & $\begin{array}{l}\text { Kepuasan Kerja mem iliki pengaruh langsung terhadap Organizational } \\
\text { Citizenship Behaviour }\end{array}$ \\
\hline H 4 & $\begin{array}{l}\text { Public Service Motivation mempengaruhi Organizational Citizenship } \\
\text { Behaviour dim ediasioleh K epuasan Kerja }\end{array}$ \\
\hline
\end{tabular}

Sumber: Adaptasi dari Cun (2012) 


\section{Hasil}

Pada penelitian ini menggunakan analisis regresi mediasi seperti yang dikembangkan oleh Baron dan
Kenny (1986) yaitu dengan causal step. Pengujian analisis melalui 4 tahapan, yaitu :

\section{Analisis Pengaruh Variabel Bebas (X) terhadap Variabel Terikat (Y)}

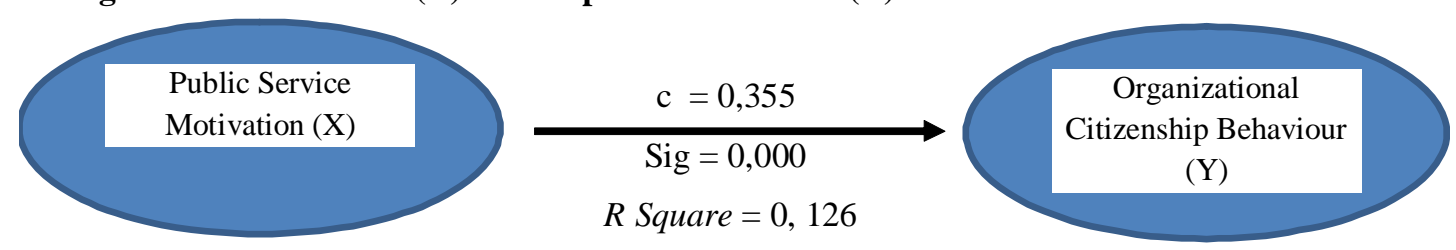

Gambar 2. Pengaruh PSM terhadap OCB

(Sumber: Hasil olah data penelitian dengan SPSS)

\section{Analisis Pengaruh Variabel Bebas terhadap Variabel Mediasi}

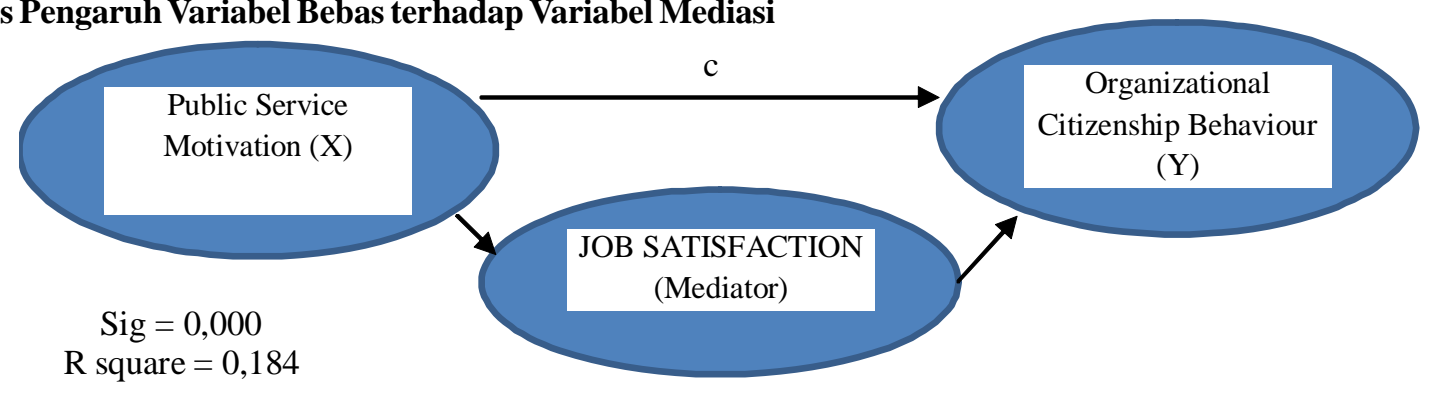

Gambar 3. Pengaruh PSM terhadap Job Satisfaction

(Sumber: Hasil olah data penelitian dengan SPSS)

\section{Analisis Regresi Mediasi dengan Regresi Berganda}

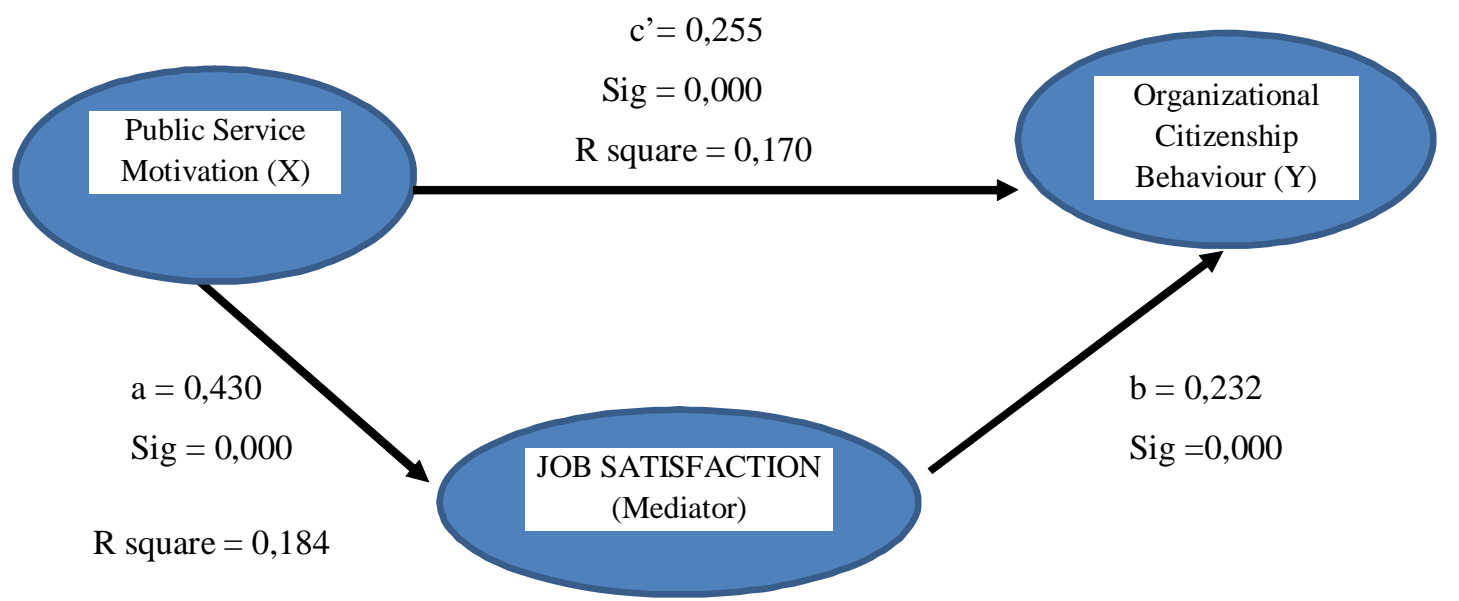

Gambar 4. Pengaruh PSM terhadap OCB dimediasi oleh Job Satisfaction (Sumber: Hasil olah data penelitian dengan SPSS)

\section{Analisis Mediasi Penuh atau Mediasi Parsial}

Tahap keempat atau tahapan terakhir dalam causal step menurut Baron dan Kenny adalah melihat apakah nilai koefisien c' signifikan, serta memiliki nilai lebih besar atau lebih kecil daripada nilai koefisien c, jika tidak signifikan dan c’> c maka merupakan mediasi penuh, dan jika signifikan dan c'< c maka merupakan mediasi sebagian (partial mediation). Makna dari mediasi sebagian (partial mediation) adalah variabel independen mampu mempengaruhi variabel dependen secara langsung meskipun tidak dimediasi oleh variabel mediasi.

\section{HASIL DAN PEMBAHASAN}

Berdasarkan nilai yang tertera pada Gambar 1, Gambar 2 dan Gambar 3 terlihat bahwa hasil uji statistik dari tahap pertama hingga tahap ketiga memiliki nilai uji regresi linier berganda yang signifikan (antara variabel Public Service Motivation dengan 
variabel Organizational Citizenship Behaviour), serta nilai c'< c $(0,255<0,355)$. Keseluruhan hipotesis dalam penelitian ini dapat dibuktikan secara positif dan signifikan sehingga keempat hipotesis tersebut dalam penelitian ini dinyatakan DITERIMA. Hal ini berarti apabila dilihat sesuai penggolongan tipe mediasi oleh Baron dan Kenny (1986) pada tahap keempat, yaitu mediasi yang dilakukan variabel kepuasan kerja termasuk mediasi sebagian (partial mediation).

$\mathrm{H}_{1}$ : Public Service Motivation memiliki pengaruh langsung terhadap Organizational Citizenship Behaviour

Hasil penelitian yang dilakukan Zhu \& Wu (2016) menyatakan PSM secara empiris berkorelasi dengan berbagai jenis perilaku organisasi dan kegiatan institusi publik. Naff \& Crum (1999) menyatakan bahwa pegawai dengan level PSM yang lebih tinggi memiliki kinerja yang lebih baik daripada rekannya dengan PSM lebih rendah. Kim (2006) juga menyatakan bahwa pegawai dengan PSM tinggi maka OCB nya pun juga lebih tinggi daripada pegawai dengan PSM rendah. Ketiga penelitian tersebut mendukung hipotesis dimana Public Service Motivation memiliki pengaruh langsung terhadap Organizational Citizenship Behaviour.

Berdasarkan pengujian validitas variabel Public Service Motivation pada penelitian ini, diperoleh factor loading dengan nilai tertinggi, yaitu 0,917 (PSM6) dan selanjutnya pada PSM7 dengan nilai 0,882 . Kedua indikator dengan nilai sangat tinggi tersebut menjelaskan bahwa yang membentuk variabel PSM pada pegawai Kantor Pertanahan Kota Administrasi Jakarta Selatan adalah bahwa pelayanan masyarakat merupakan tugas para pegawai dan pelayanan yang sungguh - sungguh sangat penting bagi mereka sehingga sudah sewajarnya untuk memberikan pelayanan yang terbaik bagi masyarakat, hal tersebut merupakan bagian dari perilaku OCB, yaitu berbuat lebih untuk organisasinya karena ingin memberikan pelayanan yang terbaik.

$\mathrm{H}_{2}$ : Public Service Motivation memiliki pengaruh

langsung terhadap kepuasan kerja

Schneider \& Vaught (1993) dalam penelitiannya menemukan bahwa pegawai di sektor pemerintahan lebih merasa puas dengan pekerjaannya dibandingkan pegawai dari sektor swasta dikarenakan aspek instrinsik motivasi dari pekerjaan mereka. Naff \& Crum (1999) juga menyatakan bahwa PSM secara signifikan berkontribusi terhadap kepuasan kerja, dan membuat merekan enggan untuk meninggalkan pekerjaannya. Hasil penelitian tersebut mendukung hipotesis PSM memiliki pengaruh langsung terhadap kepuasan kerja, bahwa motivasi memiliki peranan dalam memberikan kepuasan kerja pada pegawai.

Apabila dilihat dari hasil factor loading variabel kepuasan kerja, menunjukkan nilai paling tinggi pada indikator JS17 $(0,757)$ dan JS20 dengan nilai sebesar 0,731. Dari indikator tersebut menunjukkan bahwa yang membentuk variabel kepuasan kerja pada pegawai Kantor Pertanahan Kota Administrasi Jakarta Selatan adalah karena responden merasa cocok dan nyaman dengan pekerjaannya yang dimiliki serta pekerjaan tersebut membuat responden merasa berprestasi, ditambah lagi mereka merasa memiliki kesempatan untuk meningkatkan keahliannya sehingga hal ini dapat memotivasi pegawai dalam bekerja. Hasil ini sesuai dengan perhitungan uji analisis regresi yang menyatakan variabel Public Service Motivation memiliki pengaruh signifikan secara langsung sebesar 18,4 \% terhadap Kepuasan Kerja dengan nilai signifikansi 0,000 dan nilai korelasi sebesar 0,430 pada Kantor Pertanahan Kota Administrasi Jakarta Selatan.

$\mathrm{H}_{3}$ : Kepuasan Kerja memiliki pengaruh langsung terhadap Organizational Citizenship Behaviour

Organ (1988) berpendapat bahwa kepuasan kerja pegawai berkorelasi dengan perilaku mereka yang tampak dalam pekerjaan, namun perilaku tersebut bukan bagian dari peranan resmi yang diminta sebagai pegawai, tetapi dapat membantu keefektifan fungsi organisasi. Penelitian tersebut mendukung bahwa pegawai yang memiliki kepuasan kerja dapat memberikan perilaku ekstra yang termasuk sebagai Organizational Citizenship Behaviour.

Hasil factor loading jawaban responden atas variabel Organizational Citizenship Behaviour menunjukkan bahwa nilai tertinggi pada OCB3 yaitu bahwa responden selalu menawarkan bantuan walaupun tidak diminta, dan nilai kedua tertinggi yaitu OCB14 dimana responden merasa tidak mengambil waktu istirahat lebih dari yang ditentukan. Kedua indikator dengan nilai tertinggi tersebut merupakan bagian dari perilaku yang dapat meningkatkan kefektifan fungsi organisasi dan bermanfaat bagi Kantor Pertanahan Kota Administrasi Jakarta Selatan. Hal ini sesuai dengan hasil uji regresi yang menyatakan variabel kepuasan kerja secara signifikan memiliki pengaruh langsung terhadap 
variabel Organizational Citizenship Behaviour dengan nilai korelasi sebesar 0,232 dan nilai signifikasi sebesar 0,000 pada Kantor Pertanahan Kota Administrasi Jakarta Selatan.

$\mathrm{H}_{4}$ :Public Service Motivation mempengaruhi Organizational Citizenship Behaviour secara tidak langsung, dengan kepuasan kerja sebagai variabel mediasi.

Hasil penelitian Cun (2012) menyatakan terdapat pengaruh public service motivation terhadap kepuasan kerja dan organizational citizenship behaviour. Hal ini diinterpretasikan dengan pelayanan yang lebih baik terhadap masyarakat menghasilkan meningkatnya kepuasan kerja dan organizational citizenship behaviour. Hasil ini mendukung hipotesis bahwa Public Service Motivation mempengaruhi Organizational Citizenship Behaviour secara tidak langsung, dengan kepuasan kerja sebagai variabel mediasi.

Hasil analisis dari uji regresi berganda terhadap Public Service Motivation dan Organizational Citizenship Behaviour dengan kepuasan kerja sebagai variabel mediasi menunjukkan terdapat pengaruh secara signifikan, dengan nilai signifikansi sebesar 0,000 dan nilai korelasi sebesar 0,255. Nilai signifikansi tersebut menunjukkan bahwa variabel mediasi hanya memberikan mediasi sebagian, dimana public service motivation dapat berpengaruh secara langsung terhadap organizational citizenship behaviour baik dimediasi oleh kepuasan kerja maupun tidak.

Pada hasil penelitian yang dilakukan di Kantor Pertanahan Kota Administrasi Jakarta Selatan menunjukkan ketika PSM meningkat maka diikuti oleh peningkatan JS serta OCB. Temuan ini menunjukkan bahwa motivasi pelayanan publik diperlukan guna meningkatkan OCB pada organisasi. Indikator PSM dengan nilai paling tinggi terdapat pada pernyataan responden menyadari bahwa pelayanan masyarakat merupakan tugasnya, dan memberikan pelayanan yang sungguh-sungguh sangat penting bagi mereka. Seperti teori yang dikemukakan oleh Herzberg (1968) dalam Spector (2012) yang menyatakan motivasi berasal dari sifat pekerjaan itu sendiri, bukan berasal dari imbalan eksternal atau kondisi pekerjaan. Kebutuhan dasar manusia dibagi menjadi dua kategori, yaitu kebutuhan dasar manusia seperti kebutuhan fisiologis dan kebutuhan yang berhubungan dengan level yang lebih tinggi, kebutuhan unik manusia untuk perkembangan psikologis. Pegawai yang bekerja dengan sepenuh hati merupakan bentuk dari kebutuhan psikologis, yang merupakan bagian dari motivation factor. Hal ini sejalan dengan Visi Kantor Pertanahan yaitu "Menjadi kantor pertanahan yang memberikan pelayanan dan memiliki data pertanahan yang lengkap, akurat mudah dan pasti”. Visi tersebut ternyata dapat dimengerti oleh responden sebagai pegawai Kantor Pertanahan kota Administrasi Jakarta Selatan untuk memberikan pelayanan terbaik bagi masyarakat. Sifat pekerjaan disini dapat dipahami sebagai pekerjaan yang dapat membuat nyaman, pekerjaan yang membuat pegawai merasa berprestasi, hal ini berkaitan dengan variabel yang membentuk kepuasan kerja, karena antara motivasi dan kepuasan kerja ini terdapat hubungan yang saling mempengaruhi.

Analisis lebih lanjut dilakukan peneliti dengan membagi PSM berdasarkan bagian kerja masingmasing responden. Tujuannya adalah untuk mengetahui bagian kerja manakah yang memiliki level PSM lebih tinggi daripada lainnya dan bagian manakah yang memiliki level PSM terendah. Hasilnya dapat dilihat pada tabel sebagai berikut :

Tabel 2. Analisis Deskriptif Public Service Motivation

\begin{tabular}{lc}
\hline \multicolumn{1}{c}{ Bagian Kerja } & $\begin{array}{c}\text { Nilai rata -rata } \\
\text { PSM }\end{array}$ \\
\hline Tata Usaha & 3,81 \\
Survey, Pengukuran dan Pemetaan & 3,76 \\
Hak Tanah dan Pengukuran Tanah & 3,79 \\
Pengendalian \& Pemberdayaan Masyarakat & 3,62 \\
Sengketa, Konflik \& Perkara Pertanahan & 3,93 \\
Pengaturan \& Penataan Tanah Pemerintah & 4,06 \\
\hline
\end{tabular}

(Sumber : hasil olah data penelitian)

Setelah mengetahui level PSM terendah dan tertingg di Kantor Pertanahan Kota Administrasi Jakarta Selatan, selanjutnya peneliti ingin mengetahui adakah perbedaan antara kedua level terendah dan tertinggi tersebut, karena keduanya termasuk dalam kategori Tinggi. Peneliti mencoba menguji perbedaan kedua nilai rata-rata tersebut dengan menggunakan One Way ANOVA. Berikut merupakan hasil dari pengolahan data tersebut :

Tabel 3. Pengujian One Way ANOVA

\begin{tabular}{cccc}
\hline Indikator PSM & Mean Square & $\mathrm{F}$ & Sig \\
\hline Between group & 1,940 & 5,706 & 0,022 \\
Within group & 0,340 & & \\
\hline
\end{tabular}

(Sumber : hasil olah data penelitian) 
Berdasarkan Tabel 3 dapat diketahui bahwa nilai probabilitas signifikansi kedua level PSM yang terendah dan tertinggi adalah 0,022 . Oleh karena nilai probabilitas signifikansi $0,022<0,05$ maka dapat dikatakan kedua level tersebut meskipun termasuk dalam kategori tinggi, namun keduanya memiliki perbedaan secara signifikan. Hal ini dimaksudkan, terdapat perbedaan signifikan mengenai public service motivation pada bagian Pengendalian dan Pemberdayaan Masyarakat dengan bagian Pengaturan dan Penataan Tanah Pemerintah. Adanya perbedaan mengenai tersebut dapat diatasi misalnya dengan memberikan pelatihan yang sesuai bidang kerja masing-masing untuk meningkatkan public service motivation para pegawai. Faktor yang menjadi penyebab berbedanya level public service motivation tersebut bisa disebabkan oleh jenis dan lingkup pekerjaan yang berbeda, cara atasan langsung memimpin ataupun kondisi lingkungan kerja di tiap bagian.

\section{SIMPULAN DAN SARAN}

\section{Kesimpulan}

Public Service Motivation dapat dibuktikan berpengaruh secara langsung dan signifikan terhadap Organizational Citizenship Behaviour di Kantor Pertanahan Kota Jakarta Selatan, sehingga meningkatnya Public Service Motivation maka akan diikuti dengan meningkatnya Organizational Citizenship Behaviour di Kantor Pertanahan Kota Jakarta Selatan.

Public Service Motivation dapat dibuktikan berpengaruh secara langsung secara signifikan terhadap kepuasan kerja di Kantor Pertanahan Kota Jakarta Selatan, sehingga semakin tinggi Public Service Motivation yang dimiliki para pegawai di Kantor Pertanahan Kota Jakarta Selatan maka akan diikuti dengan peningkatan Kepuasan Kerja pegawai tersebut. Kepuasan kerja dapat dibuktikan berpengaruh secara langsung secara signifikan terhadap Organizational Citizenship Behaviour di Kantor Pertanahan Kota Jakarta Selatan, sehingga meningkatnya Kepuasan Kerja pegawai maka akan semakin meningkat Organizational Citizenship Behaviour di Kantor Pertanahan Kota Jakarta Selatan. Public Service Motivation dapat dibuktikan berpengaruh secara langsung dan signifikan terhadap Organizational Citizenship Behaviour melalui kepuasan kerja sebagai mediator di Kantor Pertanahan Kota Jakarta Selatan, sehingga semakin tinggi Public Service Motivation pegawai maka akan diikuti dengan peningkatan Organizational
Citizenship Behaviour dengan melalui peningkatan Kepuasan Kerja di Kantor Pertanahan Kota Jakarta Selatan.

Keterbatasan dalam penelitian ini salah satunya adalah karena penelitian hanya dilakukan di Kantor Pertanahan Kota Administrasi Jakarta Selatan, sehingga hasilnya hanya bisa digeneralisikan untuk instansi/lembaga yang memiliki karakteristik sama seperti Kantor Pertanahan Kota Administrasi Jakarta Selatan. Keterbatasan lainnya adalah pengujian hipotesis pada penelitian ini diolah dengan menggunakan program statistik SPSS 22 dan menggunakan tahapan pengujian dari Baron \& Kenny (1986), dengan melakukan regresi linier sederhana dan regresi linier berganda. Hal ini dikarenakan jumlah responden tidak mencukupi untuk melakukan pengujian yang lebih kompleks seperti model Structural Equation Modelling (SEM).

Beberapa hal yang dapat disarankan terkait Public Service Motivation adalah meningkatkan kekompakan tim, baik di dalam bagian kerja maupun antar bagian kerja. Kegiatan indoor maupun outdoor seperti FGD, apel pagi, makan bersama, outbound, studi banding pelayanan, merupakan hal yang bisa meningkatkan motivasi pegawai di tempat kerja sehingga bisa optimal dalam melayani masyarakat. Dari hasil pengolahan data one way ANOVA terlihat terdapat perbedaan signifikan pada level terendah dan tertinggi, maka disarankan agar dapat diberikan pelatihan pegawai sesuai kebutuhan masing-masing bagian untuk meningkatkan motivasi pelayanan kepada masyarakat.

Untuk variabel terkait Job Satisfaction, disarankan agar keterbukaan komunikasi yang baik antara staf dengan atasan maupun antara sesama staf perlu ditingkatkan agar koordinasi pekerjaan dapat dilakukan dengan baik. Untuk meningkatkan prestasi dan keahlian pegawai, atasan dapat memberikan tanggung jawab secara bergantian dalam pelaksanaan program kerja yang telah disusun. Selain itu, pegawai yang secara adil bergantian diberi kesempatan untuk mengembangkan diri seperti mengikuti pelatihan, seminar, juga dapat merasa lebih berprestasi, sehingga dapat bekerja lebih optimal.

\section{DAFTAR PUSTAKA}

Baron, R.M. \& Kenny, D.A. (1986). The moderatormediator variable distinction in social psychologicalresearch: Conceptual, strategic, and statistical considerations. Journal of Personality and Social Psychology, 51 (6), 1173 - 1182.

George, J. M. \& Jones, G.R. (2004). Organizational behaviour.(3rd ed.). New Jersey: Pearson Education. 
Joireman, J., Daniels, D., George Falvy, J., \& Kamdar, D. (2006). Organizational citizenship behaviors as a function of empathy, consideration of future consequences, and employee time horizon: An initial exploration using an in basket simulation of OCBs. Journal of Applied Social Psychology, 36(9), 2266-2292.

Kreitner, R. \& Kinicki, A. (2014), Organizational behavior. McGraw -Hill: New York.

LePine, J. A., Erez, A., \& Johnson, D. E. (2002). The nature and dimensionality of organizational citizenship behavior: a critical review and meta-analysis. Journal of applied psychology, 87(1), 52.

Liu, B., Tang, N., \& Zhu, X. (2008). Public service motivation and job satisfaction in China: An investigation of generalisability and instrumentality. International Journal of Manpower, 29(8), 684-699.

Maholtra, N. (2010). Marketing research : An applied orientation. UK: Prentice Hall.

Mukarom, Z. \& Laksana, M. W. (2015). Manajemen pelayanan publik. Bandung: CV Pustaka Setia.

Naff, K. C. \& Crum, J. (1999). Working for America: Does public service motivation make a Difference?. Review of Public Personnel Administration, 19(4): 5-16.

Ombudsman RI. (2018). Diambil dari: http:// www.ombudsman.go.id/perwakilan/news/r/pwkmasyarakat-jangan-ragu-lapor-ke-ombudsman.

Organ, D. (1988). Organization citizenship behaviour, the good soldier syndrome. Toronto: Lexington Books.

Organ, D.W., Podsakoff, P.M. \& MacKenzie, S.B. (2006). Organization citizenship behaviour: Its nature, antecedents, and consequences. Beverly Hills: Sage.

Puslitbang BPN RI. (2015). Penelitian indeks kepuasan masyarakat dalam rangka percepatan reformasi birokrasi BPN RI. Jakarta: Puslitbang BPN RI.

Perry, J.L. \& Wise, R. (1990). The Motivational base of public service. Public Administration Review, 50 (3), 367-373.

Perry, J.L. (1996). Measuring pubic service motivation: An Assessment of contruct reliability and validity. Journal of Public Adminstration and Theory, 6 (1), 5-22.

Podsakoff, P. M., Ahearne, M. \& MacKenzie, S. B. (1997). Organizational citizenship behavior and quantity and quality of work group performance. Journal of Applied Psychology, 82, 262 - 270.

Podsakoff. (2000). Organizational citizenship behaviours: a Critical reviews of theoritical and empirical literature and suggestions for future research. Journal of Management, 26 (3), 513-563.
Rast, S., \& Tourani, A. (2012). Evaluation of employees' job satisfaction and role of gender difference: An empirical study at airline industry in Iran. International Journal of Business and Social Science, 3(7)

Robbins, S. P. \& Judge, T. A. (2008). Organizational behavior (15th ed.). Boston: Pearson Prentice Hall.

Sangmook Kim.(2006). Public service motivation and organizational citizenship behaviour. International Journal of Manpower, 27 (8), 722 - 740.

Schneider, D. \& Vaught, B. (1993). A comparison of job satisfaction between public and private sector managers. Public Administration Quarterly. 17 (1), 68-83.

Shokrkon, H., \& Naami, A. (2008). The relationship of job satisfaction with organizational citizenship behavior and job performance in Ahvaz factory workers.

Smith, C.A., Organ, D.W. \& Near, J.P. (1983). Organizational citizenship behaviour: Its nature and antecedents. Journal of Applied Psychology, 68, 653-663.

Spector, Paul E. (2012). Industrial and organizational psychology research and practise (9th ed.). Singapore: John Wiley \& Sons.

Sunaryo, S. (2013). A Test of model of the relationship between public service motivation and job satisfaction, organizational citizenship behaviour. Review of Integratif Business \& Economic Research, 2(1), 384-398.

Website Menpan RB (2016). Pengaduan pelayanan publik ke ombudsman membludak, diakses dari https:// www.menpan.go.id/berita-terkini/-pengaduanpelayanan-publik-ke-ombudsman-membludak

Website Presiden RI. Mengukur Kemajuan Reformasi Birokrasi. (2015, Desember 17) diakses dari http:// www.presidenri.go.id/program-prioritas-2/mengukurkemajuan-reformasi-birokrasi.html

Weiss, D. J., Dawis R., Lofquist, L. H. \& Englan, G. W. (1966). Instrumentation for the theory of work adjustment (Minnesota Studies in Vocational Rehabilitation, XXI). Minneapolis: University of Minnesota.

Xiaogang Cun. (2012). Public service motivation and job satisfaction, organizational citizenship behaviour. The Journal Chinese Management Studies, 6 (2), 330 340.

Zhu, L. \& Wu, C. (2016). Public service motivation and organizational performance in Chinese provincial governments. Chinese Management Studies, 10 (4), 770-786. 